\title{
The Effect of Neuropeptide Y (NPY) rs 16147 Gene Polymorphism on the Blood Pressure of Chronic Kidney Disease Patients and Control Healthy in Medan, Indonesia
}

\author{
Gabriel Pardamean $^{1}$, Riri Andri Muzasti ${ }^{1,2}$, Syafrizal Nasution ${ }^{1,2}$ \\ ${ }^{1}$ Department of Internal Medicine, Faculty of Medicine, University of North Sumatera, Medan, Indonesia \\ ${ }^{2}$ Division of Nephrology and Hypertension, Department of Internal Medicine, Faculty of Medicine, University \\ of North Sumatera, Medan, Indonesia \\ Corresponding Author: Riri Andri Muzasti
}

\section{ABSTRACT}

Introduction: Chronic Kidney Disease (CKD) is a pathological condition that occurs gradually and is irreversible, characterized by structural and functional abnormalities in the kidneys that lasts for more than three months. The $\mathrm{C}$ allele in the Neuropeptide Y (NPY) RS16147 gene is closely related to an increase in the incidence of hypertension, a decrease in glomerular filtration rate, and an increase in total cholesterol levels in CKD patients.

Objective: To determine the effect of the NPY RS16147 gene polymorphism on the blood pressure of chronic kidney disease patients and control healthy in Medan Indonesia.

Methods: This study is an analytical study with a case-control design at the Haji Adam Malik General Hospital Medan from July to August 2020. All subjects had Deoxyribonucleic Acid (DNA) analysis using Polymerase Chain Reaction Restriction Fragment Length Polymorphism (PCR-RFLP) method.

Results: We obtained 100 study subjects, 43 was CKD patients with dialysis, 31 CKD patients without dialysis, and 26 control healthy groups. In this study, there were differences in the trend genotypes of NPY RS16147 polymorphism with the incidence of CKD and control healthy. We obtained a significant difference the mean systolic blood pressure patients with genotypes TT $(139,05 \pm 21,42)$ and TC/CC $(151,32 \pm 22,26)$ as evidenced by the value of $\mathrm{P}=0.00(\leq 0.05)$. The presence of the "C" allele in the NPY RS16147 gene sample
\end{abstract}

increased blood pressure in all study subjects significantly $(\mathrm{P}=0.028 ; \leq 0.05)$.

Conclusion: the "C" allele in the NPY RS16147 gene affects systolic blood pressure.

Keywords: NPY RS16147 polymorphism, Chronic kidney disease, Blood pressure

\section{INTRODUCTION}

Chronic Kidney Disease (CKD) is a pathological condition that occurs gradually and is irreversible, characterized by structural and functional abnormalities in the kidneys that lasts for more than three months. ${ }^{1}$ Globally, $11-13 \%$ of the world's population are people with chronic kidney disease. $^{2}$ In Indonesia alone, a report from the 2018 Basic Health Research by the Indonesian Ministry of Health states that $0.38 \%$ of Indonesia's population is sufferers of CKD, which is mainly dominated by people aged 65-74 years. ${ }^{3}$

Various factors are known to play an important role in causing hypertension in patients with $\mathrm{CKD}$, including age, alcohol consumption, smoking, excessive salt diet, increased body weight, and other important factors, one of which is an increase in sympathetic nerve tone. ${ }^{1}$ This condition is mediated by increased release of sympathetic neurotransmitter, Neuropeptide Y (NPY), which occurs in patients with CKD. $^{2}$ Neuropeptide Y (NPY) is a 
neuropeptide consisting of 36 amino acids, which also functions in the homeostatic and physiological processing stages of the central and peripheral nerves. ${ }^{4}$ The site of the presence of NPY is around the end of the sympathetic nerve fiber of the vascular network. The function of NPY when combined with norepinephrine is as a potent vasoconstrictor. $^{5}$

There are two methods of impact caused by NPY on cardiovascular tissue, namely as a cardio-stressor and a cardiodepressant. The cause of this opposite effect is due to the NPY receptors showing different expression patterns, as well as in terms of DPP-4 activity, ligand concentration and adrenergic activity. 4,6 Production of NPY, pathologically may be increased in cardiovascular tissue as well as receptor expression and DPP-4 (diptydyl peptidase-4).

It causes an imbalance of sympathovagal interactions, cardiac contraction, cardiac remodeling, increased angiogenesis, and proliferation, as well as inflammation-induced endothelial dysfunction in the vascular tissue. Thus, alteration in NPY activity and levels indicate a variety of pathogenic cardiovascular morbidities, such as arrhythmias, cardiac hypertrophy, heart failure, ischemia, arteriosclerosis and hypertension. ${ }^{7}$

There is a significant difference in NPY levels in patients with various nutritional status who have a history of chronic disease. Several studies have found that NPY levels in cerebrospinal fluid (CSF) and blood changed significantly in mouse models with chronic renal failure and CKD patients. Inflammation and metabolic acidosis affect the central nervous system in terms of altering the production and function of several neurotransmitters. ${ }^{8}$

Circulating NPY levels are relatively low in healthy individuals but significantly increased during the sympathetic activation condition that is observed in stressful situations such as exercise and hypoxia. NPY levels were found to be relatively high in hypertensive patients with elevated plasma norepinephrine. ${ }^{7}$ The NPY RS16147 gene polymorphism has been studied to be associated with changes in gene expression and NPY synthesis, where the $\mathrm{C}$ allele has been shown to increase the rate of gene expression thereby increasing NPY synthesis. Other studies have also shown that the C allele in the NPY RS16147 gene is closely related to a rising incidence of hypertension in people with chronic kidney disease, a decrease in glomerular filtration rate, and an increase in total blood cholesterol levels in people with chronic kidney disease. ${ }^{5}$

The previous studies that identified the effect of NPY RS16147 gene polymorphisms on the incidence of hypertension in patients with CKD influenced by race while there is no study investigate before in Indonesian population.

On this basis, the study aims to determine the effect of the NPY RS16147 gene polymorphism on blood pressure in patients with chronic kidney disease chronic kidney disease patients and control healthy, especially in the Indonesian population.

\section{METHODS}

\section{Study subjects}

An analytical study with a casecontrol design of 100 subjects at the Haji Adam Malik General Hospital Medan from July to August 2020. The study involved case and control groups that meet the inclusion criteria in the study. The inclusion criteria for cases of CKD included being at least 18 years old years, have been diagnosed with chronic kidney disease for at least 1 month, for patients with chronic kidney disease hemodialysis has been undergoing regular hemodialysis (HD) for at least 3 months, as well willing to be a research sample by signing an informed consent sheet after explanation and approval from the respondent candidates. The inclusion criteria for the control group included a minimum age of 18 years old, had no chronic kidney disease as evidenced by levels of urea and serum creatinine 
within normal limits, no history of hypertension, willing to be the study sample by signing the consent sheet after an explanation (informed consent). Patients with incomplete medical record files at the time of data collection were excluded from the research subjects.

\section{Blood pressure measurement and DNA analysis of NPY gene polymorphisms}

History and physical examination were performed on all research subjects including measurement of blood pressure using a manual mercury sphygmomanometer. Accurate blood pressure measurement is essential for diagnosis, management of CKD, and monitoring of hypertension. After a 5minute break, the blood must be measured to get the pressure value by the standard method, using a device that has been determined and calibrated regularly. The cuff that should be used is a cuff that covers $80 \%$ of the arm, and is attached to the arm until it reaches the atrium. The patient being examined must sit with his legs stretched out at the level of the floor and assisted by a back support, namely a chair. The researcher must take at least two measurements. When going to take blood pressure measurements, patients are not allowed to consume caffeine and also do exercise at least 30 minutes before. A 24hour ambulatory blood pressure measurement has been considered the best measure in the general population and patients with CKD. Blood pressure cuffs are worn for 24 hours, with measurements taken every 15 to 20 minutes during the day and every 30 to 60 minutes during sleep. Therefore, the advantage of 24-hour ambulatory blood pressure measurement is the acquisition of blood pressure results during sleep which allows for precise nocturnal physiological assessment (e.g. blood pressure should decrease> $10 \%$ during sleep) and variability in blood pressure. ${ }^{10}$

Furthermore, venous blood was collected to examine NPY gene polymorphisms by DNA extraction. DNA is extracted from a blood sample that has been mixed with preservative froze EDTA using the Gene JET TM Whole Blood Genomic DNA Kit Mini (THERMO SCIENTIFIC, EU / Lithuania) according to the manufacturer's instructions. Samples were analyzed with the TaqMan RS16147 probe (99399T / C NPY), each of which was labeled with fluorescent dye VIC and FAM, with the following probe sequence: GCTTCCTACTCCGGCACCCAGGGGG [C / T] TGGTAGTCCTGTTGGAGAGA. The $20 \mu \mathrm{L}$ volume required for real-time PCR contains $10 \mu \mathrm{L}$ of the TaqMan Genotyping Master Mix, $1.25 \mu \mathrm{L}$ of the 20 $\times$ SNP test mixture containing the DNA primer and probe, nucleases, and templates. The 96-well plate was cycling as follows: $50{ }^{\circ} \mathrm{C}$ for 1 minute (Pre-PCR stage), then $95^{\circ} \mathrm{C}$ for 10 minutes and 45 cycles of $95^{\circ}$ $\mathrm{C}$ for 15 seconds, $60^{\circ} \mathrm{C}$ for 1 minute (cycling), and $60^{\circ} \mathrm{C}$ for 1 minute (PostPCR) using a realtime 7500 PCR system (Applied Biosystems, Foster City, California).

\section{Statistical analysis}

Data were analyzed using the SPSS version 23 program. Ordinal / nominal data are presented in the form of percentages and numeric data / intervals that are normally distributed are presented in mean \pm SD and data that are not normally distributed are presented median (min-max). Normality test used Kolmogorov -Smirnov with $\mathrm{P}>0.05$ data was normal distributed. The bivariate analysis used the Chi-square for category criteria and used Fisher exact test if expected count $<5$. While for numerical variables using unpaired T-test (if data were normally distributed) or the Mann-Whitney test (if the data is not normally distributed). A correlation test was performed to assess the strength of the relationship. A multivariate analysis will be carried out using logistic regression. The p-value $<0.05$ was stated as statistically significant. 
Gabriel Pardamean et.al. The effect of neuropeptide y (NPY) rs 16147 gene polymorphism on the blood pressure of chronic kidney disease patients and control healthy in Medan, Indonesia.

\section{RESULTS}

This study is an analytical study with a case-control design at the Haji Adam Malik General Hospital Medan from July to August 2020 with the Research Ethic Committe Number 315/KEP/USU//2020 dated 24 August 2020 released by the Medical Faculty of North Sumatera University. by All subjects had Deoxyribonucleic Acid (DNA) analysis using Polymerase Chain Reaction Restriction Fragment Length Polymorphism (PCR-RFLP) method. There were 100 study subjects, with 43 CKD patients with dialysis, 31 CKD patients without dialysis, and 26 control groups (non-CKD patients). A total of 26 patients had normotension, 51 patients with first-grade hypertension, and 23 patients with second-grade hypertension. General characteristics of study subjects are presented in table (1).

The median age of the patients was 51.5 years, and there was a significant difference in age between groups in the unpaired non-parametric comparative test so that the age variable was considered as one of the determinants of blood pressure in the multivariate analysis. There was a significant difference in mean body weight between groups. The normotension group had the highest average body weight compared to the $1^{\text {st }}$ grade and $2^{\text {nd }}$ hypertension groups.

Table 1. General Characteristics

\begin{tabular}{|c|c|c|c|c|c|}
\hline \multirow[t]{2}{*}{ Variable } & \multirow[t]{2}{*}{ Total } & \multicolumn{2}{|l|}{ Groups } & \multirow[b]{2}{*}{ Grade 2 hypertension } & \multirow[t]{2}{*}{ p-value } \\
\hline & & Normotension & Grade 1 hypertension & & \\
\hline Sample & 100 & 26 & 51 & 23 & - \\
\hline Age [median (min-max)] & $51,5(22-83)$ & $27,5(23-83)$ & $54(22-80)$ & $55(28-67)$ & 0,000 \\
\hline Gender & & & & & 0,303 \\
\hline Male (n) & 50 & 10 & 29 & 11 & \\
\hline Female (n) & 50 & 16 & 22 & 12 & \\
\hline BMI (mean \pm SB $)$ & $23,47 \pm 3,77$ & $24,73 \pm 4,33$ & $22,76 \pm 3,54$ & $23,60 \pm 3,34$ & 0,212 \\
\hline Genotype & & & & & $0,017 *$ \\
\hline $\mathrm{CC}(\mathrm{n})$ & 5 & 0 & 3 & 2 & \\
\hline TC (n) & 14 & 0 & 10 & 4 & \\
\hline TT (n) & 81 & 26 & 38 & 17 & \\
\hline Chronic kidney disease & & & & & $0,000^{*}$ \\
\hline CKD with HD (n) & 43 & 0 & 31 & 12 & \\
\hline CKD without HD (n) & 31 & 0 & 20 & 11 & \\
\hline Non-CKD (n) & 26 & 26 & 0 & 0 & \\
\hline Heart failure (n) & 2 & 0 & 0 & 2 & $0,037 *$ \\
\hline
\end{tabular}

Various factors are known to play a role in the occurrence of hypertension which is one of the risk factors for chronic kidney disease, including age, diet, high salt diet, lack of exercise activity, and increased body weight. ${ }^{1}$ Logistic regression analysis in this study resulted in two variables that affect blood pressure, such as age and body weight.

This can be seen in the table (1) which shows a significant effect with a value of $p=0.034$ and $p=0.00$ for weight and age variables, respectively. The effect of age on hypertension is related to the degeneration process of the blood vessel walls, which results in a decrease in the elasticity of the arteries. ${ }^{11}$ The relationship between body weight and hypertension also involves the same route. High-fat deposition in the body triggers inflammation, which in turn causes endothelial dysfunction. ${ }^{12}$

Table (2) shows the TT genotype polymorphism is a form of Neuropeptides $\mathrm{Y}$ (NPY) is most often found in the research subjects $(81 \%)$. The second most common genotype was TC (14\%). The genotype that was rarely found was the $\mathrm{CC}$ genotype $(5 \%)$.

In the study, it was found that there was an increasing trend in the incidence of CKD in populations with the $C$ allele in the NPY RS16147 gene (table 2, p = 0.017). However, in this study, not a single healthy individual was found with the presence of the C allele in the NPY RS16147 gene. In contrast, as many as 14\% (TC genotype) 
Gabriel Pardamean et.al. The effect of neuropeptide y (NPY) rs 16147 gene polymorphism on the blood pressure of chronic kidney disease patients and control healthy in Medan, Indonesia.

and 5\% (CC genotype) of subjects with CKD had the C allele of the NPY RS16147 gene. This indicates that the NPY RS16147 gene polymorphism does not only affects individual blood pressure regulation, but also a risk factor for microvascular complications in the form of kidney failure.

Table 2. Test for differences in NPY gene polymorphism trends in all subjects
\begin{tabular}{|l|l|l|l|l|l|}
\hline Category & Genotype & & Total & \\
\cline { 2 - 4 } & TT n $(\%)$ & TC n $(\%)$ & CC n $(\%)$ & & P \\
\hline CKD Group & $55(55 \%)$ & $14(14 \%)$ & $5(5 \%)$ & $74(74 \%)$ & $0,017 *$ \\
\hline Dialysis & $42(42 \%)$ & $1(1 \%)$ & $0(0 \%)$ & $43(43 \%)$ & \\
\hline Non-dialysis & $13(13 \%)$ & $13(13 \%)$ & $5(5 \%)$ & $31(31 \%)$ & \\
\hline Control Group & $26(26 \%)$ & $0(0 \%)$ & $0(0 \%)$ & $26(26 \%)$ & \\
\hline Total & $81(81 \%)$ & $14(14 \%)$ & $5(5 \%)$ & $100(100 \%)$ & \\
\hline
\end{tabular}
Chi-square test condition are not met. Kruskal-Wallis test was performed

Table (3) shows the effect of NPY gene polymorphisms on blood pressure.

There was a significant difference in the mean systolic blood pressure of the group study with TT genotype and TC / CC genotype. The mean difference between the two groups was $12.26 \pm 5.5 \mathrm{mmHg}$ and was considered significant in the unpaired t-test with $\mathrm{p}$-value $=0.028$.

The NPY gene polymorphism RS16147 C allele showed a higher NPY activity when compared to the $\mathrm{T}$ allele. Thus the $\mathrm{C}$ allele would also be associated with an increased sympathetic nervous system activity which in turn would increase blood pressure in patients. ${ }^{13}$ In other studies it was stated that the $\mathrm{CC}$ genotype and the $\mathrm{C}$ allele on TC genotype were a risk factor for hypertension with odds ratios of 3.26 and 1.77 respectively. ${ }^{5}$ The presence of the C allele in the NPY RS16147 gene, initiates transcription of the NPY gene. Sympathetic activity generated by NPY, such as inflammation and increased heart rate plays an important role as a risk factor for patients with CKD. ${ }^{14}$

Table 3. The effect of NPY gene polymorphism on systolic blood pressure

\begin{tabular}{|l|l|l|l|}
\hline Genotype & Systolic BP(mean \pm SB $)$ & P-value & BP difference \\
\hline TT & $139,05 \pm 21,42$ & 0,028 & $12,26(5,5)$ \\
\hline TC/CC & $151,32 \pm 22,26$ & & \\
\hline
\end{tabular}

From table 3 it can be seen that the mean of SB of the TT Genotype is $139.05 \pm 21.42$, while the $\mathrm{P}$ value of TT is 0.028 while the BP difference is $12.26(5.5)$ and TC/CC shows the mean of SB is 151 ,32 $\pm 22,26$. There was a significant difference in the mean systolic blood pressure of the group study with TT genotype and TC / CC genotype.

The results of this study support research conducted by Badr et al. that in patients with chronic patients who also have a history of hypertension and without hypertension, there is a significant increase in TG, TC, LDLc and CMIT values. Badr et al. also reported that the " $\mathrm{C}$ " allele was associated with the incidence of hypertension and chronic renal failure. The results also showed that these patients had significantly increased HDLc and $\mathrm{C}$ allele genotyping of the NPY gene compared to patients in the control group. ${ }^{5}$

\section{DISCUSSION}

The neuropeptide Y (NPY) gene is one of the genes associated with blood pressure regulation. This gene is widely expressed in the peripheral and central nervous system. ${ }^{15}, 16$ Increased levels of NPY have also been reported in patients with cardiovascular disease such as acute myocardial infarction and angina pectoris. ${ }^{17}$ Studies in the last two decades have also found a correlation between the NPY RS16147 gene polymorphisms and cardiovascular events. ${ }^{18}$ This indicates that the NPY gene is associated with the incidence of hypertension in an individual.

This study found a genetic influence on systolic blood pressure. The genetic influence intended in this study is specified in the variation of the functional single gene polymorphism (SNP) of the NPY gene in the promoter region of RS16147 owned by 
each individual. This study proves that the presence of the "C" allele in the NPY RS16147 genotype has a significant effect on systolic blood pressure. Patients with this allele had significantly higher blood pressure than patients who did not express this allele. The authors noted that the mean systolic blood pressure of patients without the "C" allele in the NPY RS16147 genotype was $139.05 \pm 21.42 \mathrm{mmHg}$, while the mean systolic blood pressure of patients with the presence of this allele was $151.32 \pm$ $22.26 \mathrm{mmHg}$. Thus, the mean difference between the two groups was $12.26 \pm 5.5$ $\mathrm{mmHg}$, which makes this difference considered significant in the unpaired T-test (Table 4, $\mathrm{p}=0.028$ ).

Badr et al. reported that the "C" allele was associated with the incidence of hypertension and chronic renal failure. The CC genotype and the " $\mathrm{C}$ " allele in the TC genotype were risk factors for hypertension with odds ratios of 3.26 and $1.77 .^{5}$ The presence of the " $\mathrm{C}$ " allele in the NPY RS16147 gene increased faster transcription of the NPY gene. Sympathetic activity by NPY, such as inflammation and increased heart rate plays an important role as risk factors for CKD patients. ${ }^{14,19}$ A multicenter cohort study in Italy has shown that NPY gene polymorphisms are associated with proteinuria and increased progression of CKD. $^{20}$

In this study, not a single healthy individual was found with the presence of the "C" allele in the NPY RS16147 gene. In contrast, as many as $25 \%$ of subjects with CKD had this allele in NPY RS16147. This indicates that the polymorphism of the NPY RS16147 gene does not only affect individual blood pressure regulation, but also a risk factor for microvascular complications, in the form of kidney failure. The C allele in the NPY RS16147 gene is significantly associated with increased sympathetic tone and psychopathological stress which leads to an increased risk of cardiovascular events and is closely related to an increase in the incidence of hypertension in patients with chronic kidney disease, decreased glomerular filtration rate and increased levels of total cholesterol in CKD patients. ${ }^{4,5}$ The effect of age on hypertension is related to degeneration processes in the walls of blood vessels, which results in decreased elasticity of the arteries. ${ }^{15}$ The link between body weight and hypertension also involves the same pathway. High-fat deposition in the body triggers inflammation, which in turn causes endothelial dysfunction. ${ }^{12}$

CKD and hypertension have overlapping and closely related cause and effect. Decreased kidney function is often accompanied by an increase in blood pressure, and a continuous increase in blood pressure increases the progression of decreased kidney function. ${ }^{21}$ Several mechanisms contribute to the development of hypertension in CKD patients. Increased sympathetic tone, caused by afferent signals generated by decreased renal function, contributes to the development of hypertension in $\mathrm{CKD}^{22}$ When eGFR decreases, at this stage there is an increase in blood pressure, due to increased salt and water retention due to upregulation of the renin-angiotensin-aldosterone system (RAAS). ${ }^{23}$

This study found that patients with CKD with dialysis had more first-grade hypertension. The total number of CKD patients with dialysis who had first-grade hypertension was $72 \%$, while the rest had second-grade hypertension. Several things can explain these findings: 1) Dialysis therapy is carried out routinely, accompanied by high medication adherence, so that blood pressure is well controlled; 2) Inotropic and chronotropic failure of the heart in the early phase occurred, so that blood pressure began to decrease but the signs of heart failure had not yet appeared in the patient.

\section{CONCLUSION}

Based on the results of the study, there was a trend of Neuropeptide Y polymorphism (NPY) in all research subjects. The presence of the $\mathrm{C}$ allele in the 
Gabriel Pardamean et.al. The effect of neuropeptide y (NPY) rs 16147 gene polymorphism on the blood pressure of chronic kidney disease patients and control healthy in Medan, Indonesia.

NPY RS16147 gene was only found in individuals with chronic kidney disease with and without dialysis. This research shows the effect of NPY gene polymorphisms on blood pressure in all study subjects. It was found that there was a significant difference in the mean systolic blood pressure of the group of study subjects with the TT genotype and the TC / CC genotype as evidenced by statistical data processing which resulted in $\mathrm{P}=0.028$. This indicates that the presence of the $\mathrm{C}$ allele in the Neuropeptide $\mathrm{Y}$ gene polymorphism RS16147 plays a role in increasing the blood pressure of the study subjects. The results obtained from a study on CKD patients with and without dialysis, NPY RS16147 gene polymorphism did not affect blood pressure. There was no statistically significant difference in mean blood pressure between groups of patients with the "C" allele and without the "C" allele. In other words, the sympathetic mechanism that is mediated by the polymorphism of the $\mathrm{C}$ allele is not the only factor that plays a role in blood pressure. Further research is needed involving patients from various health centers (multicentre study), so that the study results can be applied to various populations.

\section{Authors Contribution}

The authors would like to thank the honorable my supervisors both DR.dr.Riri Andri Muzasti, M.Ked(PD), SpPD-KGH and dr.Syafrizal Nasution, M.Ked(PD), SpPD-KGH who have provided assistance to the authors related to research, especially for research conception/design, data acquisition, data analysis, result interpretation, manuscript preparation, figure and/or table design and critical revision of the manuscript so it can be finished on time.

\section{Acknowledgement: None}

Conflict of Interest: None

Source of Funding: None

\section{Ethical Approval: Approved}

\section{REFERENCES}

1. Levin A, Stevens P, Bilous R, Coresh J, De Fransisco A, et al. Notice. Kidney International Supplements. 2013;3(1):1.

2. Hill N, Fatoba $\mathrm{S}$, Oke J, Hirst J, O'Callaghan C, Lasserson D, et al. Global Prevalence of Chronic Kidney Disease - A Systematic Review and Meta-Analysis. PLOS ONE. 2016;11(7):e0158765.

3. Kesehatan, B. P d. P., 2019. Riset Kesehatan Dasar Indonesia Tahun 2018. Jakarta, Kementerian Kesehatan Republik Indonesia

4. Chang H, Fang W, Chang T, Huang S, Chang C. Association of neuropeptide Y promoter polymorphism (rs16147) with perceived stress and cardiac vagal outflow in humans. Scientific Reports. 2016;6(1).

5. Badr E, El-Aleem Hassan Abd El-Aleem A, EL-Ghlban S, Swelm A, Emara M. Relation of neuropeptide $\mathrm{Y}$ gene expression and genotyping with hypertension in chronic kidney disease. Biochemistry and Biophysics Reports. 2019;19:100666.

6. Sommer, W. H., Lindstrom, J., Sun, H. \& Passer, D., 2010. Human NPY promoter variation $\mathrm{rs} 16147: \mathrm{T}>\mathrm{C}$ as a moderator of prefrontal NPY gene expression and negative affect. HUMAN MUTATION mutation, in brief, 31(8), pp E1594-E1608.

7. Tan, C. M., Green, P., Tapoulal, N. \& Lewandoski, A. J., 2018. The Role of Neuropeptide $\mathrm{Y}$ in Cardiovascular Health and Disease. Front Physiol., Volume 9, pp.1-13.

8. Lu L, Zou Y-C, Wang M, Huang Y-F, Chen D-X, Wei L-B. Neuropeptide Y levels are associated with nutritional status and cardiovascular events in adults with chronic kidney disease. European Journal of Clinical Nutrition. 2015;69:717-721.

9. Rysz J, Banach M, Cialkowska-Rysz A, Stolarek R, Barylski M, et al. Blood Serum Levels of IL-2, IL-6, IL-8, TNF- $\alpha$ and IL-1 $\beta$ in Patients on Maintenance Hemodialysis. Cellular \& Molecular Immunology. 2006;3(2):151-154.

10. Ku, E., Lee, B. J., Wei, J.\& Weir, M. R., 2019. Hypertension in CKD: Core Curriculum 2019. AJKD, 74(1), pp. 120131. 
Gabriel Pardamean et.al. The effect of neuropeptide y (NPY) rs 16147 gene polymorphism on the blood pressure of chronic kidney disease patients and control healthy in Medan, Indonesia.

11. Liao D, Arnett D, Tyroler H, Riley W, Chambless L, Szklo M, et al. Arterial Stiffness and the Development of Hypertension. Hypertension. 1999;34(2): 201-206.

12. Brandes R. Endothelial Dysfunction and Hypertension. Hypertension. 2014;64(5): 924-928.

13. Fu, X.-F., Zhang, X., Wang, D.-J. \& Zhao, B., 2013. Neuropeptide Y Gene Promoter 399T/C Polymorphism Increases Risk of Ischaemic Stroke. Balkan Medical Journal, 30(2), pp. 147-150.

14. Amdur R, Feldman H, Gupta J, Yang W, Kanetsky P, Shlipak M, et al. Inflammation and Progression of CKD: The CRIC Study. Clinical Journal of the American Society of Nephrology. 2016;11(9):1546-1556.

15. Adrian T, Allen J, Bloom S, Ghatei M, Rossor M, Roberts G, et al. Neuropeptide Y distribution in the human brain. Nature. 1983;306(5943):584-586.

16. Gray T, Morley J. Neuropeptide Y: Anatomical distribution and possible function in the mammalian nervous system. Life Sciences. 1986;38(5):389-401.

17. Corr L, Burnstock G, Poole-Wilson P. Effects of age and hyperlipidemia on rabbit coronary responses to neuropeptide $\mathrm{Y}$ and the interaction with norepinephrine. Peptides. 1993;14(2):359-64

18. Shah S, Freedman N, Zhang L, Crosslin D, Stone D, Haynes C, et al. Neuropeptide Y Gene Polymorphisms Confer Risk of EarlyOnset Atherosclerosis. PLoS Genetics. 2009;5(1):e1000318.
19. Zoccali C, Leonardis D, Enia G, Postorino M, D’Arrigo G, Tripepi G, et al. Heart rate, age and the risk of progression to kidney failure in patients with CKD. Journal of Nephrology. 2012;25(Suppl. 19):20-27.

20. Zoccali C, D'Arrigo G, Leonardis D, Pizzini $\mathrm{P}$, Postorino M, Tripepi G, et al. Neuropeptide $\mathrm{Y}$, and chronic kidney disease progression: a cohort study. Nephrology Dialysis Transplantation. 2018;33(10):18051812.

21. Bakris G, Williams M, Dworkin L, Elliott W, Epstein M, Toto R, et al. Preserving renal function in adults with hypertension and diabetes: A consensus approach. American Journal of Kidney Diseases. 2000;36(3):646-661.

22. Converse R, Jacobsen T, Toto R, Jost C, Cosentino F, Fouad-Tarazi $\mathrm{F}$ et al. Sympathetic Overactivity in Patients with Chronic Renal Failure. New England Journal of Medicine. 1992;327(27):19121918.

23. Pugh D, Gallacher $P$, Dhaun N. Management of Hypertension in Chronic Kidney Disease. Drugs. 2019;79(4):365379.

How to cite this article: Pardamean G, Muzasti RA, Nasution S. The effect of neuropeptide $y$ (NPY) rs 16147 gene polymorphism on the blood pressure of chronic kidney disease patients and control healthy in Medan, Indonesia. International Journal of Research and Review. 2021; 8(8): 319-326. DOI: https://doi.org/10.52403/ijrr.20210844 